\title{
Hospital Use in Hagerstown
}

\author{
MARGARET D. WEST and RUTH M. RAUP
}

$\mathrm{D}$ URING RECENT DECADES, many changes have taken place in patterns of medical care. Besides new methods of preventing and treating illness and disability, new forms of organizing and financing medical and hospital care have emerged making possible more efficient provision of services and a lighter burden of medical care costs for some individuals. Changes in the character of the population, such as the increase in the proportion of older persons, have altered the relative importance of certain diseases and injuries. What has been the effect of these and other changed conditions on the utilization of hospital care?

Since the early 1920's the Public Health Service has conducted a series of studies on the health status in Hagerstown, Md., a small city selected as representative in demographic characteristics of communities in the eastern United States. Among these studies have been household morbidity surveys, the first conducted in the period 1921-24 (1) and the latest during 1955-57 (2).

The 1955-57 survey showed that most of the hospital care of the surveyed population was provided in the Washington County Hospital in Hagerstown. The same hospital provided most of the hospital care for residents of the area in 1921-24. Because this hospital maintains an excellent index of patient discharges covering both the earlier and the later survey periods, a valuable opportunity was presented for comparison of the city's rates and patterns of hospitalization over an interval of about 35 years.

\section{Methods}

Information on hospitalization in the 192124 and 1955-57 surveys was collected by check- ing the name of each individual in the survey against the discharge records of the Washington County Hospital for the period of his inclusion in the survey. The population surveyed in 1921-24 numbered 9,946 individuals, representing about one-third of the city's total population at that time $(28,064$ in the 1920 census $)$. The group in 1955-57, about one-twentieth of the total population of 36,260 in the 1950 census, was made up of 1,868 individuals, including 22 who died during the survey period.

As a basis for computing hospitalization rates, the number of individuals surveyed was multiplied by the period of coverage of the individuals to give the total person-years of experience on which information was obtained. In the 1921-24 survey, the total number of personyears of experience reported on was 18,790. Person-years in the more recent survey totaled 2,935 , with about half of the individuals covered for 1 year and most of the rest for 2 years.

Both the 1921-24 and 1955-57 survey populations were generally representative of the total Hagerstown population in sex and age distribution, as reported in the 1920 and 1950 censuses. The earlier sample was picked by interviewing all households in sections of the city which represented different economic classes. The 1955-57 sample was drawn at random from households listed in the Hagerstown city directory. Only white households were included in the 1921-24 survey, whereas about 3 percent of the persons surveyed in 1955-57 were Negroes.

Mrs. West is chief of the Health Service Requirements Branch, and Miss Raup, public health research analyst, in the Division of Public Health Methods, Public Health Service. 


\section{Hospital Use}

Over the past 35 years, patterns of hospitalization in Hagerstown as reflected in use of the Washington County Hospital by the 1921-24 and 1955-57 surveyed populations have changed markedly. Perhaps the most striking change is the increase in hospital admissions and in total days of hospitalization per year.

Hospital admissions among the 1955-57 surveyed population occurred at a rate about $51 / 2$ times that for the 1921-24 group-105 per 1,000 person-years as compared with 18 per 1,000 . Among females, who in both surveys had higher admission rates than males, the size of the increase was even greater-from 21 per 1,000 to 134 per 1,000, or a growth of more than 6 times. Admission rates among men increased about $43 / 4$ times, from 15 per 1,000 to 71 per 1,000 .

Patients in the more recent period tended to stay for shorter periods than did those admitted 35 years earlier. Whereas in the 1921-24 survey the average length of stay was 12.5 days, by 1955-57 the average had dropped to 7.6 days, a decrease of well over one-third. The decrease was particularly marked among females, whose average stay dropped from 13.2 to 6.9 days. Among males the decrease was proportionately smaller, from 11.5 to 9.2 days.

These decreases, however, only partly offset the increase in admissions in total effect on hospital days per year. So great was the increase in admissions that, despite the one-third decrease in average length of stay, total annual days of hospitalization received by the 1955-57 surveyed population exceeded by more than three times, relatively, the days of care received by the 1921-24 group. As shown in figure 1, the rate increased from 228 days per 1,000 person-years in the earlier period to 797 days in the latter. Among males the rate increased about $33 / 4$ times as compared with a $31 / 3$ increase in the rate for females.

Only a small part of the increase in hospitalization can be explained by a growth in the proportion of persons admitted more than once during a given year. The number of different individuals hospitalized increased from 17.3 per 1,000 persons to 91.3 per 1,000 , or almost as much as the hospital admission rates. The increase in repeated hospitalizations was somewhat greater among females than among males.
Figure 1. Annual hospital days per 1,000 person-years for populations surveyed in Hagerstown, Md., 1921-24 and 1955-57, by sex

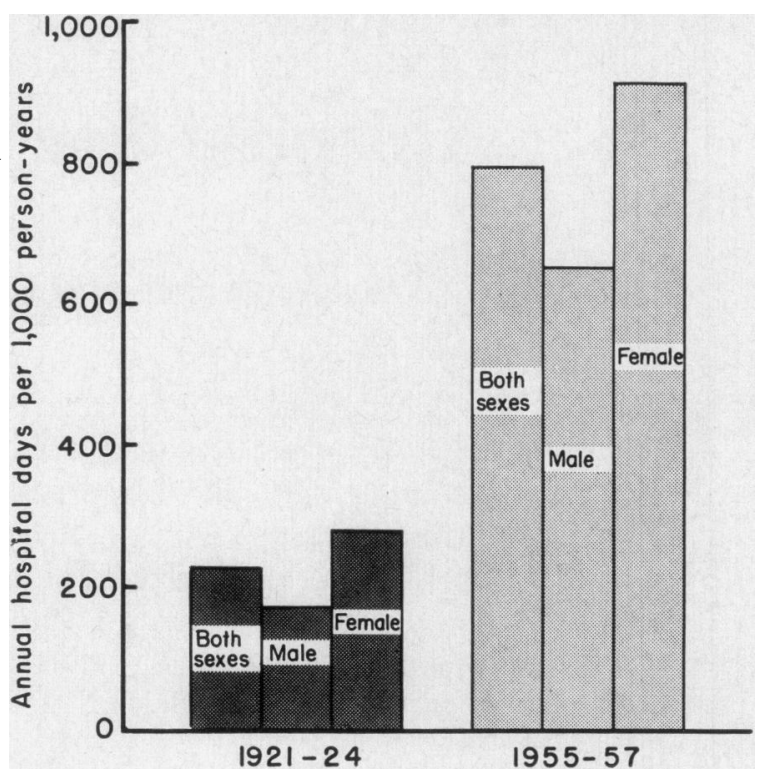

Hospitalization rates based on records of the Washington County Hospital slightly understate total hospital use to the extent that in both 1921-24 and 1955-57 certain members of the surveyed populations received all or part of their hospital care in hospitals outside Hagerstown. In the later period, as determined from interview replies, total admission rates, including "outside" hospitalizations, were about 10 percent higher than admission rates for the Washington County Hospital alone. There was some tendency for persons going to "outside" hospitals to stay for longer periods, raising the average length of stay from 7.6 days for Washington County Hospital admissions to 8.2 for all hospitalizations. Although it has not been possible to get similar detail on outside hospitalizations among the 1921-24 population, W. C. Dando, assistant to the administrator of the hospital, is of the opinion that the proportion so receiving care has not changed significantly in the past 35 years.

\section{Variations by Age}

Increases in hospitalization rates were found in all age groups, although the size of the increase was greater for some groups than for others. The largest increases both in admis- 
Table 1. Hospital admissions per 1,000 personyears of experience of populations surveyed in Hagerstown, Md., 1921-24 and 1955-57, by age group

\begin{tabular}{r|r|r|r}
\hline Age group (years) & $1921-24$ & $1955-57$ & $\begin{array}{c}\text { Times } \\
\text { increased }\end{array}$ \\
\hline Total & 18 & 105 & 5.8 \\
\hline $5 n$ Under 5 & 9 & 67 & 7.4 \\
$15-24$ & 58 & 2.8 \\
$25-44$ & 21 & 115 & 5.0 \\
$45-64$ & 21 & 139 & 6.6 \\
65 and over. & 19 & 87 & 4.6 \\
\hline
\end{tabular}

sions and in annual hospital days occurred among the youngest and the oldest age groups (table 1, fig. 2). Among children under 5 years, admission rates increased 7 times and annual days 10 times, while the comparable increases for persons 65 years old and over were 13 and 12 times. Each of the intervening age groups, however, also showed increases in hospital care.

Among the intervening age groups, increases in admissions tended to exceed increases in total days of care per year. Whereas admission rates rose by amounts ranging from just under three to almost seven times, total days of care in no case increased more than 2 to $21 / 2$ times. The differential between the increase in admissions

Figure 2. Annual hospital days per 1,000 person-years for populations surveyed in Hagerstown, Md., 1921-24 and 1955-57, by age

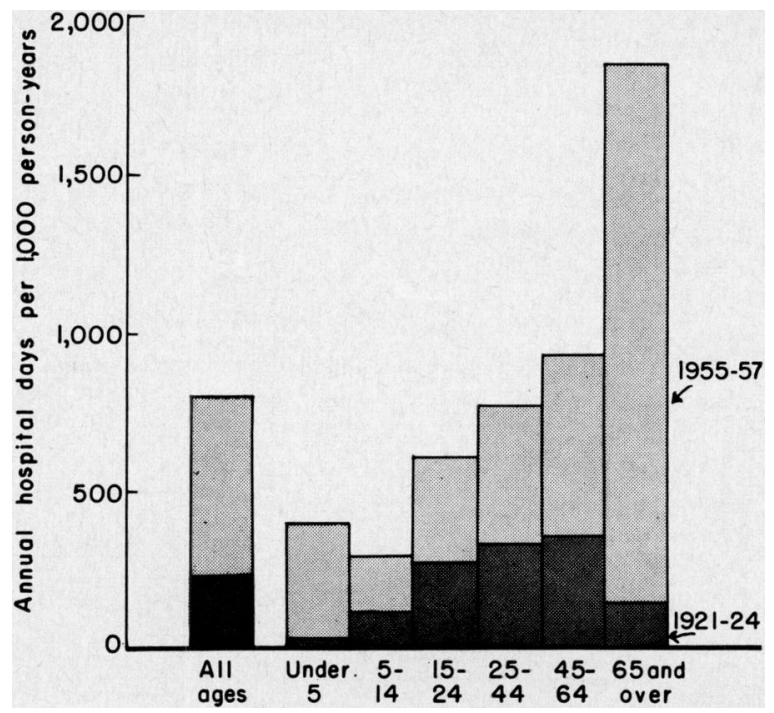

and the increase in days of care was greatest among persons 15-24 and 25-44 years old, and least among children 5-14 years of age. These differences reflect variations by age in the extent of change in average length of stay.

Although the average stay for the total survey groups declined about one-third, it decreased as much as two-thirds among persons 25-44 years old (fig. 3). Other age groups experiencing a marked decline were the 15-24 and 45-64. Relatively little change occurred in the shorter average stays of children under 15 or in the longer average stays of persons 65 and over. The small increase in stay among children under 5 can be explained at least in part by a decrease in the share of the caseload admitted for short-stay tonsillectomies.

Figure 3. Average length of stay per hospital admission for populations surveyed in Hagersfown, Md., 1921-24 and 1955-57, by age

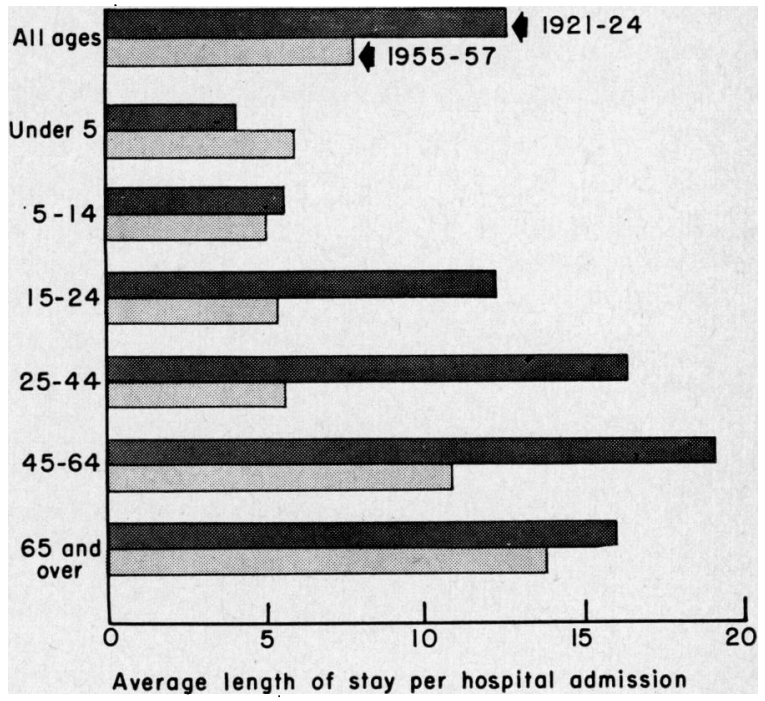

Over the past 35 years the proportion of the Hagerstown population in the age groups having the highest hospitalization rates has increased. Between 1921-24 and 1955-57, the proportion of the surveyed population 65 years old or over doubled, rising from one-twentieth to one-tenth. There was an increase also in the second oldest group, 45-64, from about onesixth to almost one-quarter of the total. The increase in hospitalization rates was sufficiently general among all age groups, however, that the 
Table 2. Hospitalization rates $^{1}$ among surveyed populations in Hagerstown, Md., with adjustment for change in age composition of population, 1921-24 and 1955-57

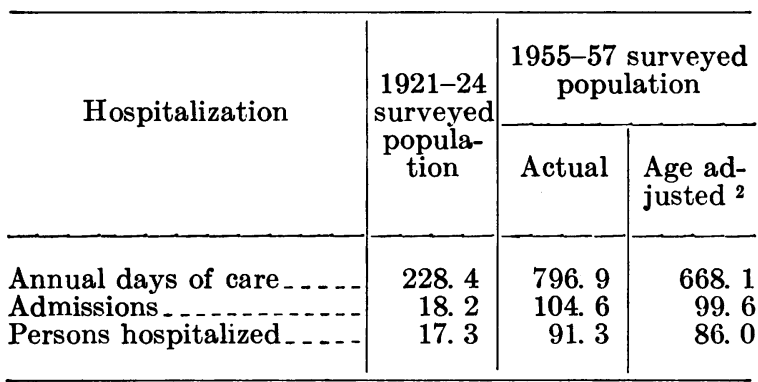

1 Per 1,000 person-years.

2 Rates expected if population with 1921-24 age composition had been hospitalized at 1955-57 agespecific rates.

increase in age of the $1955-57$ population accounts for only a small part of the overall increase in hospitalization. Even if the age composition of the population had stayed constant, as in table 2, annual hospital days relative to population still would have increased almost three times, hospital admission rates about five times, and persons hospitalized more than four times.

\section{Diagnosis}

It might be expected that a few outstanding diagnoses or diagnostic groups would account for most of the increase in hospitalization between the 1921-24 and 1955-57 survey periods. Actually there were increases in care, in terms of annual days of hospitalization or hospital admission rates, for practically every diagnosis or diagnostic group studied. This is shown in some detail in figure 4 and table 3.

The diagnostic groups showing the largest proportionate increases in hospitalization were circulatory diseases (including heart), genitourinary disorders, neoplasms, and deliveries. Such other categories as respiratory diseases, diseases of the digestive system, and accidents, however, also accounted for substantial increases in care. The only diagnostic group having a decrease in annual days of care was infectious and parasitic diseases, and this was surprisingly small.

Hospitalization rates for specific diseases or conditions within the diagnostic groups, al- though based on small numbers of cases, provide similar evidence of a general growth in hospital use. Between the earlier and the later survey periods, only three diseases listed-tuberculosis, typhoid, and mastoiditis-disappeared as causes of hospitalization in this general hospital. Rates of care for appendicitis, tonsillectomies, and arthritis and rheumatism remained about the same or dropped somewhat. For all other diagnoses listed, hospital admissions and annual days of care increased by amounts ranging from twice to more than 50 times. Even pneumonia accounted for $2 \frac{1}{2}$ times as many admïssions and annual days in $1955-57$ as in 1921-24.

Increased hospitalization for the delivery of babies accounts for a significant part of the increase in hospital use among women of childbearing age. In the 1921-24 surveyed population, women $15-44$ years old were ad-

Figure 4. Annual hospital days per 1,000 person-years for populations surveyed in Hagerstown, Md., 1921-24 and 1955-57, by diagnosis

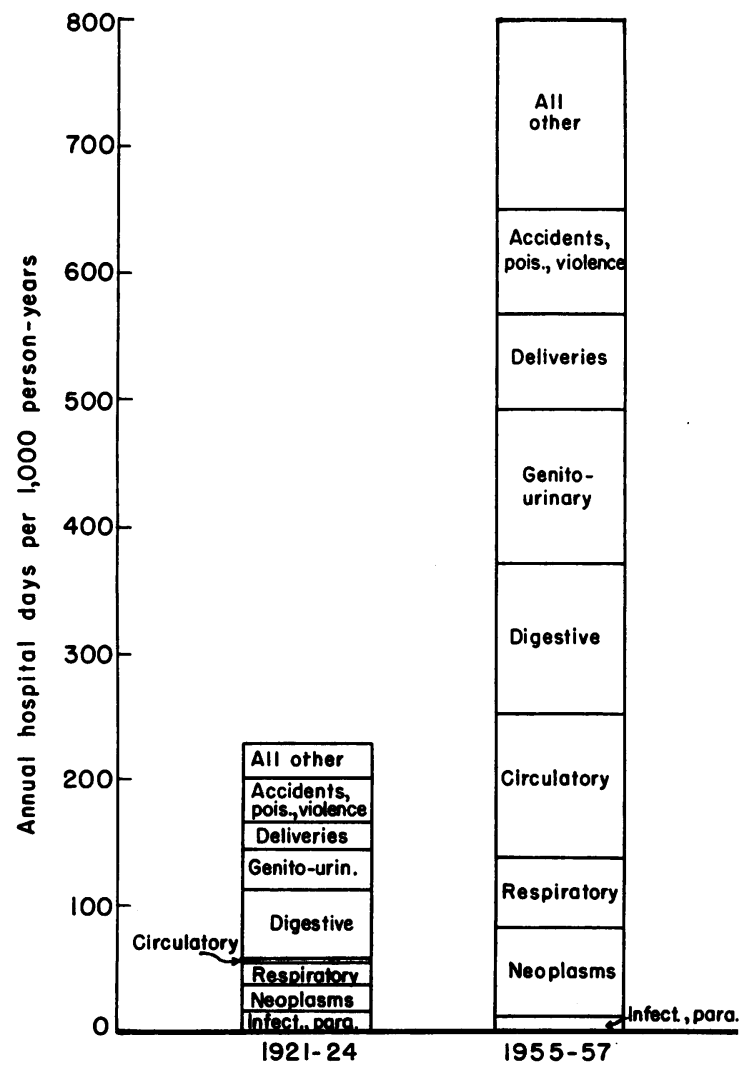


Table 3. Hospitalization rates by diagnosis, surveyed population in Hagerstown, Md., 1921-24 and 1955-57

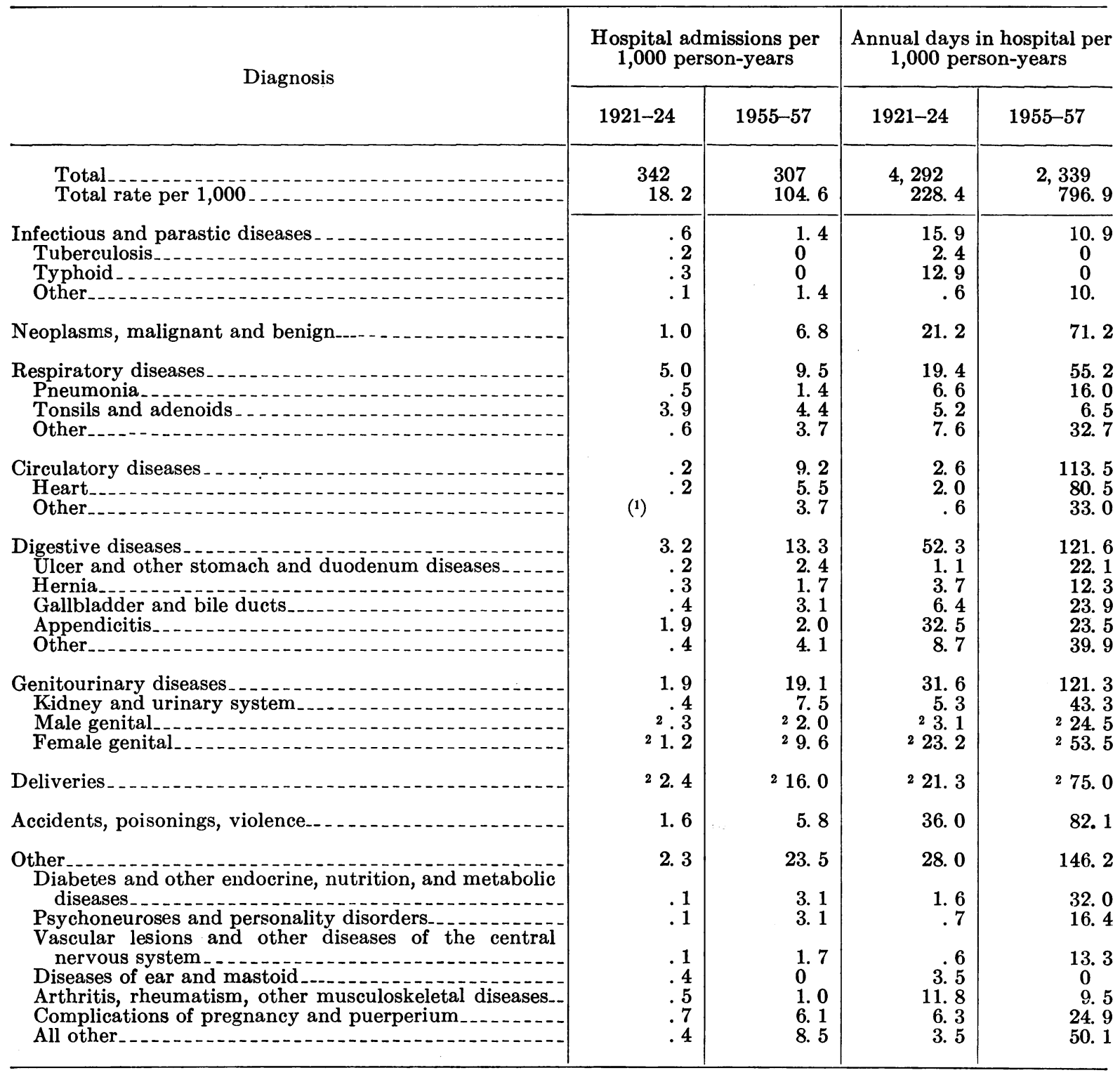

1 Less than 0.05 .

2 Rate in relation to total person-years of experience. mitted to the Washington County Hospital for deliveries at a rate of 7.2 per 1,000; in the 1955-57 population the comparable rate was 71.3 per 1,000 , or about 10 times as great. Annual days of hospital care for deliveries increased at a somewhat lesser rate, reflecting an almost two-thirds decrease (from 12.9 to 4.7 days) in the average length of stay for delivery cases.
Birth statistics for the whole of Washington County support the hypothesis that the increase in delivery cases among the surveyed populations was related to a trend toward hospitalization for deliveries rather than to some other factor such as an increase in the birth rate. Between 1921 and 1956 the birth rate in Washington County scarcely changed; actually it decreased slightly. At the same 
Table 4. Hospitalization rates ${ }^{1}$ for women of childbearing age, compared with rates for men in same age groups, surveyed populations in Hagerstown, Md., 1921-24 and 1955--57

\begin{tabular}{|c|c|c|c|}
\hline Hospitalization, by sex & $1921-24$ & $1955-57$ & $\begin{array}{l}\text { Times in } \\
\text { creased }\end{array}$ \\
\hline Admissions & & & \\
\hline $\begin{array}{l}\text { Females 15-44 years: } \\
\text { Including deliveries } \\
\text { Excluding deliveries } \\
\text { Males 15-44 years.... }\end{array}$ & $\begin{array}{l}28.7 \\
21.7 \\
13.4\end{array}$ & $\begin{array}{r}201.8 \\
130.5 \\
52.5\end{array}$ & $\begin{array}{l}\text { 7. } \\
6.9 \\
3.9\end{array}$ \\
\hline Annual days in hospital & & & \\
\hline $\begin{array}{l}\text { Females 15-44 years: } \\
\text { Including deliveries... } \\
\text { Excluding deliveries } \\
\text { Males 15-44 years... }\end{array}$ & $\begin{array}{l}416 \\
326 \\
204\end{array}$ & $\begin{array}{r}1,058 \\
724 \\
349\end{array}$ & $\begin{array}{l}2.5 \\
2.2 \\
1.7\end{array}$ \\
\hline
\end{tabular}

1 Per 1,000 person-years.

time, in the second half of this period alone, the proportion of all Washington County births occurring in a hospital increased about fourfold, rising from 26 percent in 1940 to 97 percent in 1956.

Even among women of childbearing age, however, the trend toward hospitalization for deliveries can be only one of a number of factors explaining the increase in hospital use. If we recompute the admission rates and annual days of care of women in this age group so as to exclude delivery cases, as shown in table 4 , we find that over the past 35 years hospitalization for causes excluding deliveries increased almost as much as did hospitalization including deliveries. In both 1921-24 and 1955-57, moreover, women 15-44 years old were hospitalized at rates well above those of men in the same age category, whether or not deliveries are included.

\section{IIIness and Death Rates}

Changes in hospitalization patterns can be expected to be related in part to changes in patterns of morbidity and mortality in the community. In Hagerstown, the incidence of certain chronic diseases is reported to have risen. There have been increases also in the proportion of persons dying from chronic illnesses and in the proportion of people dying in the hospital.
Because both the 1921-24 and the 1955-57 surveys had as their primary objective the measurement of illness rates, it is possible to compare changes in hospitalization rates with changes in reported sickness rates, at least for selected chronic conditions. Among the illnesses compared, the most common pattern of change was one of increase in both hospitalization and illness rates but the increase in hospitalization was greater. Thus the rate at which heart disease was reported in 1955-57 was approximately twice that for 1921-24, but during the same period hospital admissions and annual hospital days for this diagnosis rose 25 and 40 times respectively.

Evidence of change in causes of death in Hagerstown is found in death reports for the whole of Washington County in the years 1922 and 1956. Although the resident death rate for all causes showed only a slight decline (from 11.6 to 10.0 per 1,000 population), there was a noticeable shift from acute toward chronic illness in the cause of death, as shown in table 5. Infant death rates also were down by about two-thirds. Although information on deaths in other age groups is not available for years as early as 1922, between 1930 and 1956 alone the proportion of total deaths occurring among persons under 15 years of age declined from 15 to 8 percent, and the proportion among persons 45 years and over increased from 67 to 84 percent.

Deaths in the hospital in Hagerstown have increased in relation to total population although they have decreased in relation to the number of admissions to the hospital. In

Table 5. Resident death rates in Washington County, Md., by selected cause, 1922 and 1956

\begin{tabular}{|c|c|c|}
\hline Cause & 1922 & 1956 \\
\hline $\begin{array}{l}\text { Deaths per 1,000 population } \\
\text { Typhoid and diphtheria } \\
\text { Diarrhea and enteritis. } \\
\text { Pneumonia and influenza. } \\
\text { Disease of early infancy } \\
\text { Cancer } \\
\text { Diseases of the heart } \\
\text { All other }\end{array}$ & $\begin{array}{r}\text { 11. } 6 \\
.2 \\
.7 \\
1.0 \\
.8 \\
.9 \\
2.0 \\
6.0\end{array}$ & $\begin{array}{l}10.0 \\
0 \\
0 \\
.2 \\
.4 \\
1.5 \\
4.4 \\
3.5\end{array}$ \\
\hline Infant deaths per 1,000 live births.- & 85. 4 & 29. 0 \\
\hline
\end{tabular}

Source: Maryland State Health Department. 
1955-56 there were 6.7 deaths in Washington County Hospital for every 1,000 residents of the county, compared with 2.5 per 1,000 in 192223 , or an increase of about $2 \frac{1}{2}$ times over the earlier period. As a proportion of total deaths among county residents, Washington County Hospital deaths rose from 10 percent in 1922-23 to 37 percent in 1955-56. The number of deaths per 1,000 episodes of hospitalization fell by about one-third (from 47.2 to 30.7 per 1,000 ) in connection with the large increase in hospitalizations that did not terminate in death.

\section{Physician Supply}

While hospitalization rates among the surveyed populations increased between 1921-24 and $1955-57$, the relative supply of physicians remained about the same. The actual number of physicians in Washington County increased by about one-third, from 59 in 1923 to 82 in. 1956, but this increase did little more than keep pace with the increase in the population during the period. The ratio of physicians to population scarcely changed, rising from 99 per 100 ,000 in 1923 to 104 per 100,000 in 1956. If the comparison is limited to physicians in private practice, the ratio is 99 per 100,000 in both periods. Any increase between 1923 and 1956 was almost entirely confined to physicians in public health, industrial medicine, and other positions distinct from private practice.

Most physicians in Hagerstown reportedly see more patients in a day or week today than they did some years ago. Not many of them work longer hours; on the contrary, most of them are said to have more real free time. Rather, the organization of practice has changed. More patients are seen in the office or at the hospital, and fewer in their homes. Where home calls are required, transportation is less of a problem. Also, according to Dr. E. F. Poole, the secretary of the Washington County Medical Society, there is more cooperation among physicians, whether informally or through partnerships or other organized arrangements, thus making services more readily available when needed.

Medical practice in Hagerstown resembles that in other parts of the Nation in that it has become increasingly specialized since the 1920's.
Table 6. Physicians in Washington County, Md., by type of practice and specialty, 1923 and 1956

\begin{tabular}{|c|c|c|}
\hline \multirow{2}{*}{$\begin{array}{c}\text { Type of practice and specialty of } \\
\text { physicians }\end{array}$} & \multicolumn{2}{|c|}{$\begin{array}{l}\text { Number of } \\
\text { physicians }\end{array}$} \\
\hline & 1923 & 1956 \\
\hline Total $\ldots \ldots$ & 59 & 82 \\
\hline $\begin{array}{l}\text { Private practice } \\
\text { General practice } \\
\text { Practice limited to specialty } \\
\text { Anesthesiology } \\
\text { Dermatology } \\
\text { Internal medicine } \\
\text { Obstetrics, gynecology } \\
\text { Ophthalmology, otorhinolar- } \\
\text { yngology } \\
\text { Orthopedic surgery } \\
\text { Pathology } \\
\text { Pediatrics } \\
\text { Radiology } \\
\text { Surgery } \\
\text { Urology } \\
\text { Not in private practice. }\end{array}$ & $\begin{array}{r}58 \\
51 \\
7 \\
0 \\
0 \\
1 \\
0 \\
4 \\
0 \\
0 \\
0 \\
1 \\
1 \\
0 \\
1\end{array}$ & $\begin{array}{r}78 \\
38 \\
40 \\
1 \\
1 \\
4 \\
3 \\
7 \\
1 \\
2 \\
6 \\
3 \\
9 \\
3 \\
4\end{array}$ \\
\hline
\end{tabular}

Source: Washington County Medical Society and American Medical Association directories.

Whereas in 1923 only about one out of eight private practitioners in Washington County limited their practice to a specialty, by 1956 this share had grown to about one out of two (table 6). Special significance for hospital care trends can be found in the increased numbers of specialists in surgery, urology, anesthesiology, obstetrics, pathology, radiology, and other types of practice involving hospital service.

\section{Hospital Beds}

One of the factors related to the growth of hospital use in Hagerstown may have been the increase in the supply of hospital beds in the area. From 80-90 beds in 1922-23, Washington County Hospital's capacity grew to 268. beds in 1955-56. The ratio of beds to the population of Washington County increased from 142 to 340 per 100,000 . But does this increase in beds necessarily mean that hospital admissions were facilitated?

Two facts suggest that the pressure on available beds in the Washington County Hospital was greater in the recent survey period than in the earlier period. First, between 1922-23 and 1955-56 the use of the hospital, as measured by 
the number of patients admitted and total annual patient days, increased faster than did the ratio of beds to population. While the ratio of beds to population increased $21 / 2$ times, hospital admissions increased almost seven times and the total annual patient days approximately quadrupled.

Second, the proportions of the hospital's available beds that were in use on any given day tended to be higher in the later period than in the earlier. In 1922-23 the average daily census represented about two-thirds of available beds. The $1955-56$ average occupancy, in contrast, was about four-fifths of capacity.

In the later survey period, the availability in Washington County of some nursing home care may have slightly relieved the pressure for long-term hospital care of chronically ill or convalescing patients. Nursing homes were practically unknown in the county in the 1920's. In 1956-57, according to current State plans under the hospital and medical facilities construction (Hill-Burton) program, the county had 327 nursing home beds, with 250 admissions per year.

\section{Socioeconomic Factors}

Possible relationships between increased hospitalization rates and changes in socioeconomic status can be measured only in general terms, since there is no comparative information on the occupational and educational characteristics of the surveyed populations, and only a few such data for the population of Hagerstown as a whole. In Hagerstown, as in most other urban areas of the United States, the proportion of the working force in professional, technical, and related occupations has increased. More women are working. Educational levels have risen. These and other socioeconomic changes, which conform generally with national trends, have established a basis for increased popular appreciation of the value and convenience of hospitalization as compared with home care of the sick and injured. At the same time, throughout this period Hagerstown's basic character as a relatively self-sufficient trading center whose principal industries are manufacturing and railroading has remained substantially the same.

\section{Insurance}

Other studies have shown a relationship between hospital utilization and hospital insurance coverage. It is possible that in recent years the growth of insurance coverage has encouraged some people in Hagerstown to make greater use of the hospital than would have been made without such insurance. While the earlier Hagerstown survey was conducted before the establishment of the first hospital prepayment plan in the United States, by 1955-57 an estimated three-fifths of all Washington County Hospital patients had insurance and about three-fifths of the total bill to patients was being paid for by insurance. The average cost of care in the Washington County Hospital is about six times higher today than it was 35 years ago, having risen from $\$ 3.15$ per patientday in 1923 to $\$ 18.30$ in 1956 . This high cost of hospitalization has virtually required the development of insurance or some other means of spreading the financial burden over a wider segment of the population.

\section{Related Findings}

In overall magnitude the hospitalization rates for the surveyed populations in Hagerstown are roughly comparable to those found in similar populations of the same general time periods. The $1955-57$ rates agree closely with rates found in the 1956 Public Health Service survey of general hospital use in the Nation, conducted by the Census Bureau (3). The Hagerstown survey's admission rate of 104.6 per 1,000 population, adjusted to 114.5 per 1,000 to include hospitalizations outside the Washington County Hospital, compares with a Public Health Service-Census survey rate of 117 per 1,000 for nonmetropolitan places with populations of 10,000 to 50,000. Average length of stay for the Hagerstown surveyed population (including outside hospitalization) was just over 8 days, ranging from 5 days to 14 days from the youngest to the oldest age groups. The average stay for cities of comparable size, as found in the Service's survey, was 7.2 days.

While comparative information is not readily available for the earlier survey period, the use of the Washington County Hospital among the 
1921-24 survey population was roughly similar in amount to the use of that hospital by the population of Washington County as a whole in 1922. Thus, annual days of hospital care in relation to population were only slightly higher for the county population than for the surveyed population. For both the Washington County residents and the 1921-24 surveyed population, average length of stay in the Washington County Hospital was about 12 days.

\section{Summary and Conclusions}

Two household morbidity surveys conducted by the Public Health Service in Hagerstown, Md., in 1921-24 and 1955-57, together with a concentration of hospitalization in one local hospital, provided the basis for a comparison of rates and patterns of hospitalization in the early 1920's and the mid-1950's. It was found that over this 35-year period, hospitalization rates in Hagerstown had increased three times in terms of annual days of care and 51/2 times in terms of admissions.

No single factor accounted for the increase in hospitalization. There was a small growth in the proportion of persons having more than one admission during a given year. The rate of hospitalization increased in all age groups, although the rate of increase was somewhat higher among children under 5 years and persons 65 years and over. The proportion of older persons in the population approximately doubled between 1921-24 and 1955-57.

There were increases in care for practically every diagnostic group studied. Only a part of the large increase in care among women of childbearing age could be attributed to an increase in hospitalization for the delivery of babies. Other diagnostic groups showing larger than average increases for all ages included circulatory diseases, genitourinary disorders, and neoplasms.
Average length of stay in the hospital decreased well over one-third between the earlier and the later surveys, but this decrease only partly offset the effect of increased admission rates in raising total hospital days. The greatest decrease in length of stay was among persons 25-44 years old. Very little change occurred in the lengths of stay of children under 15 and persons 65 and over.

One factor making for increased hospitalization probably was the increased occurrence of certain chronic illnesses, but for the particular illnesses studied the hospitalization rates tended to increase faster than the illness rates. Analysis of death rates showed that more people were dying of chronic diseases and that an increasing proportion of deaths were occurring in the hospital.

While hospital care increased, the supply of physicians relative to population remained about the same in 1955-57 as in 1921-24. The ratio of hospital beds to population was greater in the later period than in the earlier, but not enough greater to keep pace with the increase in hospital use. Hospital insurance coverage facilitated hospitalization in the later period to the extent that it paid for all or part of the hospital bills of about three-fifths of the patients.

\section{REFERENCES}

(1) Turner, V. B. : Hagerstown health studies : An annotated bibliography. PHS Pub. No. 148. Washington, D.C., U.S. Government Printing Office, 1952, $38 \mathrm{pp}$.

(2) West, M. D., and Altenderfer, M. E.: Illness and medical care in Hagerstown, Maryland. I. The prevalence of chronic disease in $1955-57$ as measured by household interviews. Washington, D.C., U.S. Public Health Service, October 1958, 45 pp. Multilithed.

(3) Odoroff, M. E., and Abbe, L. M.: Use of general hospitals: Demographic and ecologic factors. Pub. Health Rep. 72: 397-403, May 1957. 